Short Communication

\title{
PREPARATION AND EVALUATION OF CO-CRYSTALS OF CARBAMAZEPINE WITH GLUCOMANNAN
}

\author{
SHARWAREE HARDIKAR* , ASHOK BHOSALE, SWATI VANAVE, BHAGYASHREE KAMATHE \\ Department of Pharmaceutics, Pune District Education Association's Seth Govind Raghunath Sable College of Pharmacy, Saswad, District- \\ Pune, Maharashtra 412301 India \\ Email: sharwareehardikar@gmail.com
}

Received: 11 Jun 2017 Revised and Accepted: 31 Aug 2017

\begin{abstract}
Objective: The objective of the present work was to inhibit transformation of carbamazepine anhydrous to its dihydrate form in aqueous medium by adopting the co-crystal approach.
\end{abstract}

Methods: Co-crystallization of carbamazepine and glucomannan as co-former was carried out by solution mediated phase transformation. The solution of carbamazepine and glucomannan in ethanol (95\%) was agitated for $2 \mathrm{~h}$ and the co-crystals obtained were recovered after $24 \mathrm{~h}$.

Results: Co-crystal formation due to hydrogen bonding between carbamazepine and glucomannan as a co-former was confirmed by FTIR study. Inhibition of transformation of co-crystal of carbamazepine to carbamazepine dihydrate in aqueous medium was confirmed by SEM.

Conclusion: Inhibition of transformation of carbamazepine co-crystal to its dihydrate form resulted in its improved dissolution. Dissolution efficiency of carbamazepine in its co-crystal was increased up to $79.26 \%$ within 30 min.

Keywords: Carbamazepine, Co-crystals, Glucomannan, Ocimum basilicum

(C) 2017 The Authors. Published by Innovare Academic Sciences Pvt Ltd. This is an open-access article under the CC BY license (http://creativecommons.org/licenses/by/4.0/) DOI: http://dx.doi.org/10.22159/ijpps.2017v9i10.20656

Carbamazepine transforms to its dihydrate form when it comes in contact with the aqueous medium. Since dihydrate form of carbamazepine is three times lesser soluble $(0.12 \mathrm{mg} / \mathrm{ml})$ as compared to its anhydrous $(0.38 \mathrm{mg} / \mathrm{ml})$ form; such transformation is a critical parameter that affects its dissolution and bioavailability [1]. It is reported in the literature that co-crystal formation of carbamazepine is a suitable approach to increase its rate of dissolution. Transformation of carbamazepine to dihydrate form is prevented when carbamazepine is in its co-crystal form. This is so, as in the co-crystal structure the hydrogen bonding occurs between the appropriate functional groups of drug and co-former. There are two possible hydrogen bonding sites in carbamazepine structure-' $\mathrm{N}$ '-of amine and ' $\mathrm{C}$ ' of carbonyl; and hence carbamazepine transforms to dihydrate in an aqueous medium. These sites are expected to undergo hydrogen bonding with co-former during co-crystallization processes [2-4].

In crystal engineering, hydrogen bonding is the strongest and key interaction in the co-crystal formation. Glucomannan is polyoxygenated compound and contains hydroxyl groups in abundance. Hydroxyl group is highly polar and capable of forming hydrogen bonds with other polar molecules. Therefore glucomannan isolated from the seeds of Ocimum basilicum was selected as a coformer in the present study [5]. At present study co-crystallization of carbamazepine was carried out by adopting solution-mediated phase transformation (SMPT) [6]. The hydrogel was isolated from the seeds of Ocimum bacilicum by the method reported earlier. Glucomannan present in the hydrogel was precipitated with $95 \%$ ethanol at $4{ }^{\circ} \mathrm{C}$ by following the procedure reported by Chua $\mathrm{M}$ et al.; 2012 [7, 8]. FT-IR spectrum of Glucomannan was obtained on IR spectrophotometer (Shimadzu, FTIR-8400S, Japan) using $\mathrm{KBr}$ powder. The scan was evaluated for the presence of principle peaks of glucomannan to confirm its purity. In FTIR spectrum of the glucomannan (fig. 1) the broad peak at $3217 \mathrm{~cm}^{-1}$ resulted from the stretching vibration of $\mathrm{O}-\mathrm{H}$ group which is moderately strong hydrogen bonding group [9]. The peaks at $2808 \mathrm{~cm}^{-1}, 1604 \mathrm{~cm}^{-1}$ and $1381 \mathrm{~cm}^{-1}$ are assigned to- $\mathrm{CH}_{2}$ stretching vibration and two $\mathrm{C}-\mathrm{H}$ bending modes respectively [8].

Carbamazepine and glucomannan in 1:1 stoichiometric ratio were dissolved in ethanol $(95 \%)$ to prepare their saturated solution. The solution was continuously agitated for $2 \mathrm{~h}$ by adding more amount of ethanol (95\%) as required to keep both the components in solution. The solution was kept aside or $24 \mathrm{~h}$ to obtain co-crystals of carbamazepine. Co-crystals equivalent to $0.1 \mathrm{gm}$ of carbamazepine was weighted accurately and evaluated for content uniformity by the method reported in Indian Pharmacopoeia. It was found to be $97.91 \% \pm 0.81$ [10].

FTIR of carbamazepine co-crystals showed distinct shifts in the absorption peaks of carbamazepine drug. The characteristic peak for-NH vibration at $3464.27 \mathrm{~cm}^{-1}$ was found to be shifted to 3402.5 $\mathrm{cm}^{-1}$. The peak at $1674.27 \mathrm{~cm}^{-1}$ due to $\mathrm{C}=0$ stretching was found to be shifted to $1620.26 \mathrm{~cm}^{-1}$. The absorption band at $1597.11 \mathrm{~cm}^{-1}$ characteristics for-NH deformation observed in carbamazepine drug was found to be absent in the spectrum of co-crystal (fig. 2 and 3). These frequency shifts were due to hydrogen bonding between carbamazepine and glucomannan in the co-crystal form [5].

Inhibition of transformation of carbamazepine co crystal to carbamazepine dihydrate was expected due to its co-crystallization and was confirmed from scanning electron microscope (SEM) imaging. SEM images were taken of plain carbamazepine and its co-crystal; both recovered after immersing them in $0.1 \mathrm{~N} \mathrm{HCl}$ for $30 \mathrm{~min}$. Samples were sputter coated with a thin layer of gold-palladium under argon vacuum prior to analysis. SEM was performed using a KV beam acceleration voltage. The SEM images are shown in (fig. 4). Plain carbamazepine was converted to the dihydrate form; as evident from the formation of distinct needles on the surface of carbamazepine particles. The SEM images of co-crystal of carbamazepine clearly exhibited inhibition of transformation to less soluble dihydrate form of carbamazepine. This was the major cause of dissolution improvement of the carbamazepine in its co-crystal form [11].

Dissolution efficiency of plain carbamazepine and its co-crystal equivalent to $100 \mathrm{mg}$ was determined by the procedure reported by Khan K. A.; 1975 [12]. The dissolution rate was determined by using USP dissolution apparatus II. The medium used was $0.1 \mathrm{~N} \mathrm{HCl}(900 \mathrm{ml})$ and the rotational speed of the paddle was kept at $100 \mathrm{rpm}$. The temperature of the dissolution medium was maintained at $37 \pm 0.5^{\circ} \mathrm{C}$ throughout the study. The $5 \mathrm{ml}$ aliquots were withdrawn, at predetermined time intervals, sufficiently diluted and absorbances were measured at 284 
$\mathrm{nm}$. There was increase in dissolution efficiency of carbamazepine in its co-crystal form when compared to that with plain carbamazepine.
Dissolution efficiency was increased from $30.84 \% \pm 1.9$ to $79.26 \% \pm 2.32$ in first $30 \mathrm{~min}$ and was statistically significant.

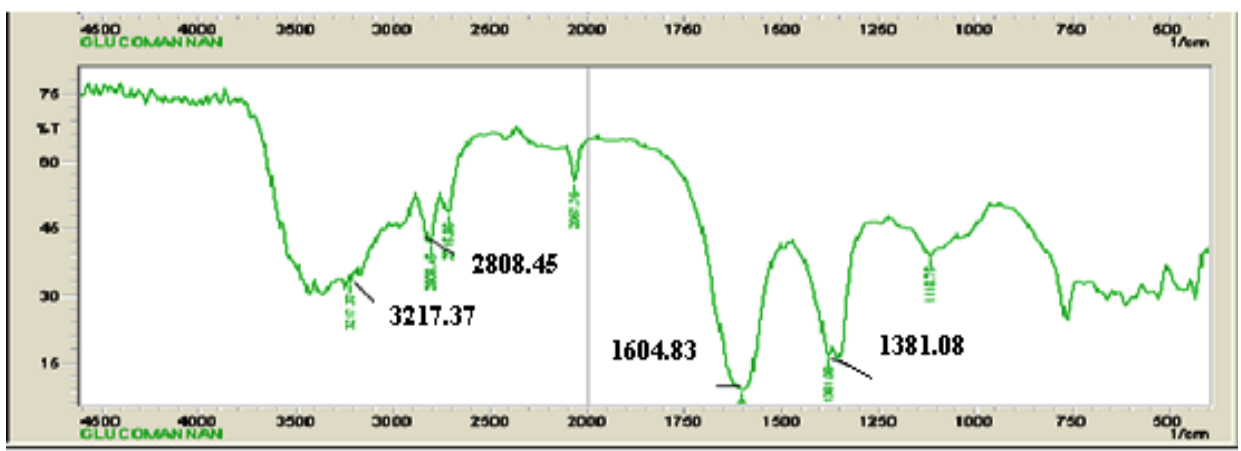

Fig. 1: FTIR spectrum of glucomannan

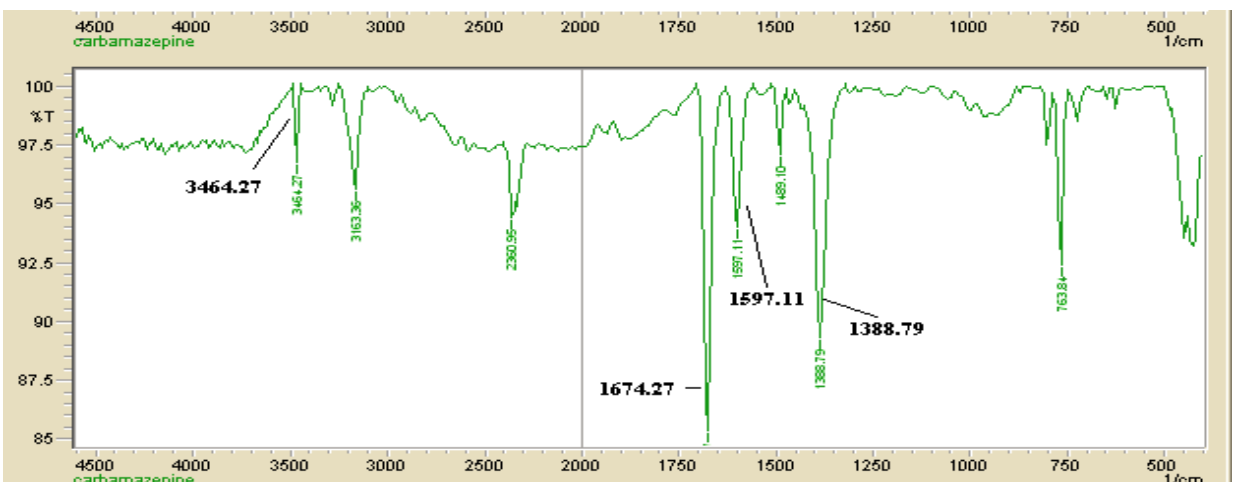

Fig. 2: FTIR spectrum of carbamazepine

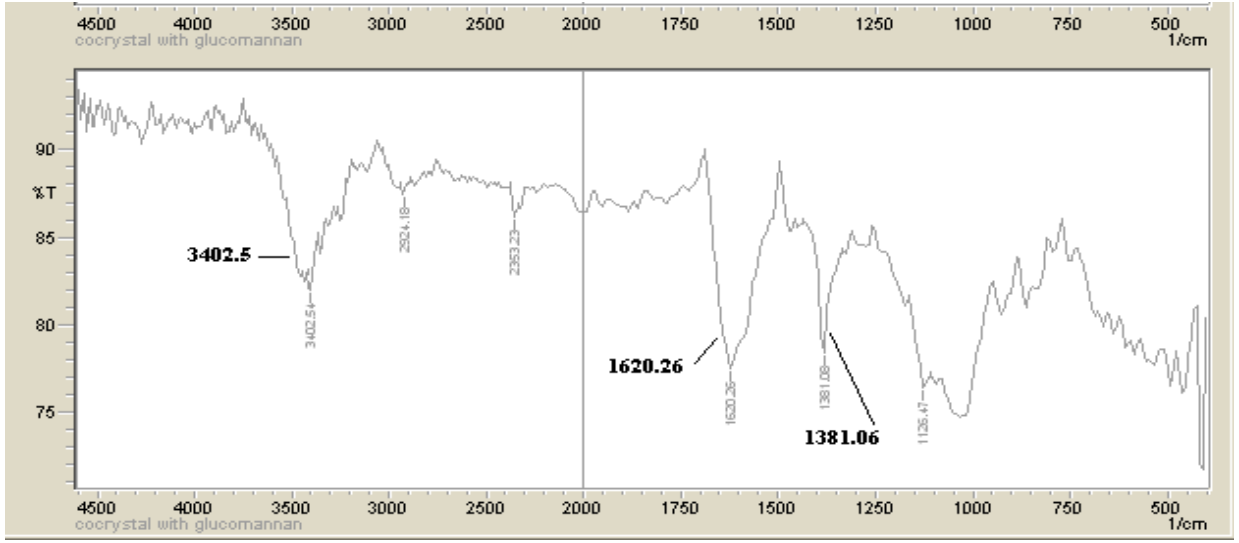

Fig. 3: FTIR spectrum of co-crystal of carbamazepine and glucomannan

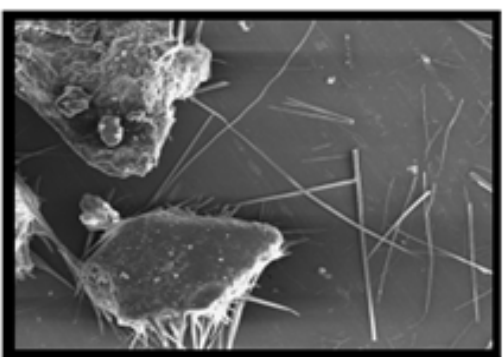

A:Carbamazepine

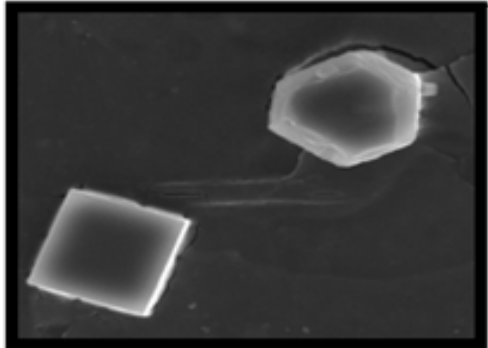

B: Co-crystal.

Fig. 4: SEM images of carbamazepine (A) and it's co-crystal with glucomannan (B) 


\section{AUTHOR CONTRIBUTION}

SHARWAREE HARDIKAR: Data analysis and interpretation and Critical revision of the article.

ASHOK BHOSALE: Design of the work

SWATI VANAVE: Data collection and drafting the article.

BHAGYASHREE KAMATHE: Data collection and writing the manuscript.

\section{CONFLICTS OF INTERESTS}

There is no any conflict of interest

\section{REFERENCES}

1. Khoo V. Process induced phase transformation of carbamazepine dihydrate to its polymorphic anhydrates. Powder Technol 2013;236:114-21.

2. Ali S, Karim Z, Aholghasem J. Solubility and dissolution rate of carbamazepine-cinnamic acid co-crystal. J Mol Liq 2013;187:171-6.

3. Fukte SR, Wagh MP, Shilpi R. Coformer selection: an important tool in co-crystal formation. Int J Pharm Pharm Sci 2014;6:9-14.

4. Harris RK, Ghi PY, Puschmann H, Apperley DC, Grisser UJ, Hammond RB, et al. Structural studies of the polymorphs of carbamazepine; its dihydrate and two solvates. Org Proc Res Dev 2005;9:902-10.

5. Rao CNR. Basic concepts, Instrumentation and techniques: chemical applications of infrared spectroscopy. Academic Press: New York and London; 1963.
6. Zhang GG, Henry RF, Borchardt TB, Lou X. Efficient co-crystal screening using solution mediated phase transformation. J Pharm Sci 2007;96:990-5.

7. Hardikar SR, Bhosale AV, Chaundkar D, Saindane A. Dissolution and bioavailibity enhancement of carbamazepine. Int J Pharm Pharm Sci 2013;5:395-400.

8. Chua M, Chan K, Hocking TJ, Williams PA, Perry CJ. Methodologies for the extraction and analysis of konjac glucomannan from corms of A. konjac K. Koch. Carbohyd Polym 2012;87:2202-10.

9. Szakonyi G, Zelko R. Water content determination of super disintegrants by means of ATR-FTIR spectroscopy. J Pharmaceut Biomed 2012;63:106-11.

10. Indian Pharmacopoeia. Government of India, Ministry of Health and Family Welfare, I: Controller of Publications, Delhi; 1996.

11. Sandler N, Gordan KC. Visualizing the conversion of Carbamazepine in aqueous suspension with and without the presence of excipient: a single crystal study using SEM and raman spectroscopy. Eur J Pharm Biopharm 2006;64:326-35.

12. Khan KA. The concept of dissolution efficiency. J Pharm Pharmacol 1975;27:48-9.

\section{How to cite this article}

- Sharwaree Hardikar, Ashok Bhosale, Swati Vanave, Bhagyashree Kamathe. Preparation and evaluation of co-crystals of carbamazepine with glucomannan. Int J Pharm Pharm Sci 2017;9(10):318-320. 